\title{
Healing Salves: Contingent Knowledge and Satisfying Surprises in Kiribati
}

\author{
Nick Bardo ${ }^{1}$ \\ Colorado Mesa University, USA
}

\begin{abstract}
Through the creative analytic practice of autoethnography and systematic sociological introspection, the author engages the subjectivity of narrative self in relation to a story involving treatment by an indigenous healer in the Republic of Kiribati. Through the lens of narratology, existential introspection, and ethics the author informs the moving vantage of the present through reflection on the micro personal and macro socio-cultural educational processes that bear influence on the narration and perception of a lived experience in hindsight. Through storying and reflecting through these lenses, this process problematizes the present story, but also yields degrees of greater awareness. This process of systematic sociological introspection is framed by Freeman's (1997) notion of narrative integrity. That is, through reflection and reframing of the past, the author hopes to focus upon the possibilities of wider metacognitive perspective for both himself and the reader in the future.
\end{abstract}

KEYWORDS: Autoethnography, Ethics, Narrative Epistemology, Narratology.

In hindsight I see the village of Notoue, on the northern islets of Tarawa in the republic of Kiribati. The shallow shadows and bright light suggest a sun high in the afternoon sky. My hair is matted with sweat, wet to the touch and limp across the rings of a salt stained pillow as I lie on my side. I arrived two months before as a member of the United States Peace Corps, a government sponsored program dedicated to promoting world peace and friendship through cultural exchange and training.

I bend into a fetal ball and grunt from my gut as I try to clear my throat of mucous. The white gauze of my mosquito net, its folds illuminated in the equatorial sun, hangs from the dried pandanus leaf thatch of the kia-kia. It is this stilted open sided sleeping platform I lie on, a structure framed with the gnarled beams of salt stained soft woods. A sulphurous low tide rot fills the air. I squint my eyes towards the haze of horizontal blue pastel waters. Purple storm clouds gather above the lagoon and intersect with the black bark of wet mangrove roots. Over the course of three days, the inconvenience of a slight fever and sore throat grew to a semi-conscious haze of shivering chills, hallucinations, and taut skin on my bloated throat.

The first morning, I woke and felt the familiar scratch of a cold. I traced the discomfort to my activities the night before. I downed dozens of cups of Kava mixed with well water singing with the village men, smoked a handful of ni moko, the island cigars rolled from shaved Irish cake tobacco and dried pandanus leaf, and broke out in allergic reaction. As I pissed into the mangroves under the full moon in a kava stupor, the itching began on the backs of my hands. Something was

${ }^{1}$ Corresponding Author E-mail: nbardo@coloradomesa.edu 
reacting with my skin, and welts grew across my hands as I itched and eventually passed out. That first morning when I woke, my throat itched.

The pain at the back of my mouth and fever grew worse over the day. I tried to pass it off, and swallowed my limited Tylenol to feel slightly better before the fever returned. That night at dusk, I winced swallowing my can of mackerel and old rice. On the second morning, I doubled over in pain to swallow water. That afternoon I crushed the last two tablets of my Tylenol into a sour powder with my molars, moving the paste in my mouth with my tongue.

On the third day, I could no longer massage saliva from my mouth into my throat, and spit the liquid into a plastic mug next to my pillow. Without water or food, my body fell limp with sweat. Fruit flies landed on my face and feet, probing without disturbance as my uvula pushed forward into my mouth.

The afternoon of the third day I began hallucinating. I saw my damp pink pillow, ringed with salt lines. The pillow presented a Harvard business school case study about Southwest airlines to me. We talked about the possibilities of future strategies, and other voices offered their two cents to the conversation. The shadows of scorpions ran below my eyes. In moments of lucidity I feared losing my grip on reality.

During that afternoon my friend Tsimmy peered through the mosquito net. He frowned and furrowed his brow. Tendrils of ni moko smoke rose from his hand as he waved his hands and spoke in clear enunciation.

"Ko rangi aoraki Nikora... Karuoa Ibonga." He was going to find Takaako, the local healer. For three days I had been able to play it off, and I read into our shared guilt from the late night of Kava drinking he had invited me to. On the third afternoon I was too weak to convince him to let it be.

I shook my head in deliberate agreement, "Eng."

Tsimmy mounted my bicycle and set off towards the crushed coral road, under the bright light and scant shadows of the mid-afternoon sun. The green canopy of the palm trees mingled with the reflective waxy leaves of the breadfruit trees, the winds rising as purple clouds gathered.

Tsimmy returned with an old woman propped side saddle on the rear rack of my bike. The ruts of deep folds framed her sun-battered face. Her hair was long, to her waist, and completely white. She both grimaced and smiled as she tied the mosquito net to the posts of the kia kia as I lay on my back. I see her face in a dusty haze or setting island sun, her white hair rising in the winds.

She placed her bony fingers on my swollen throat, her finger pads gentle and soft. As she massaged the area around my carotid arteries in widening circles, pain echoed in my head. I thought to myself that there was no way this was helping me - who was this woman? She was certainly respected by the village, and I was. By this time, a crowd of children gathered to watch the healer. They crowded the kia-kia and hung on our movements and my winces. I smelled baby powder as she spread talc on my throat in widening circles. Unable to clear the saliva that gathered in my mouth, or move my head from her hands, the liquid ran down my cheek.

The healer's voice rolled over me in discordant phonemes as she spoke to me in halting Gilbertese. I didn't understand most of what she said and turned my gaze to Tsimmy. He raised his eyebrows and held up three fingers. I looked to the healer, who held up three sinewy fingers in as well. She shook the fingers towards me and signaled to a child at her side to fetch water. The children grew excited. I closed my eyes, winced as I attempted to clear my throat, and understood that something was going to happen three times.

The child returned with a rusted can of well water and I turned my head to watch as she poured the yellowish opaque well water over her right hand and wrist. She flung the excess water to the dusty ground and formed the right index and middle finger of her hand into a claw. She moved to steady my chest with her left hand as she rose above me. The healer placed her fingers 
into my mouth and I shrank away from her, spitting her fingers out of my mouth. What the fuck was she doing? I turned my head to the side, closed my eyes, and pursed my lips in a grimace. She's not a doctor...I don't even know who this woman is. I opened my eyes and looked to Tsimmy and the faces of the children with wide eyes crowding the platform.

The healer took my head with her hands and looked at me, silent. She held her three fingers above my eyes again. I wanted to get out of there. I needed to get real medical attention. I felt the eyes of the children, of my friend Tsimmy, and the healer. They were not going anywhere until something happened three times.

I dropped my hands to my side and gripped the smooth bark of the kia-kia frame. She opened my mouth with her fingers and steadied my chest again. Her slight frame rose over me as she reached her small hand further and further into my throat. I breathed deeply through my nose as she pressed with the weight of her body, a force that surprised me, focused in her pointer and middle fingers at the back of my windpipe. Her arm shook from the pressure she applied. Tears filled my eyes and my lips shuddered in a gag around her wrist. I flexed, shook, and gripped the side of the kia-kia with closed eyes and held breath.

She pulled her saliva-coated hand from my throat quickly and my stomach shuddered in dry heaves. I turned my head to the side and gazed towards the dusty sand under the platform. Streams of spittle hung from my mouth and nose. My heart thundered in my swollen throat in searing pain. I held up my head again and looked to the thatch roof as I winced while trying to suppress painful coughs. The healer shook two bony fingers over my eyes. I gripped the sides of the platform and do not remember the next two rounds of the healer's ministrations. When she finished, it was dark and the dancing flame of the kerosene lantern outlined her face in the winds. Tsimmy handed the healer a pack of Rothman cigarettes and a bag of dried fish and she walked into the darkness of the night, before the rains pelted the thatch through the night.

I did not hallucinate again, and after a night of pain and fever, I felt sure enough the next morning to walk and ride three hours towards the nearest CB radio. I didn't tell Tsimmy. I was tired of everything, and told one of the children to let people know I had gone. I left and did not return to the village for another two weeks. At the CB I was summoned to the local clinic across the lagoon. That morning I held my throat and shuddered in the well of the one-engine wooden wa as the narrow outrigger crashed across waves on the open blue water for three hours. I took five intravenous bags of fluid and IV antibiotics at the clinic, afterwards, the attending doctor told me,

\section{You are lucky you didn't have kidney failure. You are severely dehydrated.}

I told people the healer had nearly killed me. In the months that followed I did not hesitate echoing this to my British, American and Australian friends, to islanders who spoke English, and in letters to my friends and family in the United States. I pointed to the fact that the infection returned again and again as evidence that her dirty fingers had pressed some bacteria deep inside my throat.

Many nights I gathered with westerners on the capital island. We would laugh and trade stories about the backwardness and naiveté of island knowledge in our exchange. In our cultural echo chamber, I felt the familiar massage of a superior narrative that bound us and our developed worldviews together.

Our stories of condescension, such as mine with the healer, worked to rationalize a certain amount of guilt. My petty worries, unearned entitlement as a privileged white male westerner, and lack of practical knowledge were exposed in light of the profound poverty and existential marginalization on the outer islands in the republic of Kiribati. In that foreign social field, I was 
like a child, where my largely academic knowledge was meaningless and practically worthless. The knowledge I possessed could only be empowered through tales where I could denigrate the islands and double down on what I knew to be right, and of value. The story with the healer was a stamp of experiential valor to my western audience, an adventure story where I was both the victim and a hero, reclaiming the superiority of my habitas and empowering my knowledge while at the same time undergoing the dangerous indignity of island medicine.

There was also the guilt of what our mission entailed as Peace Corps volunteers, something that was apparent to those willing to see beyond their own idealism. The shadow of colonization under the British extended into the description of our work - to teach English, the tongue of colonial history and oppression - a language slowly eradicating traditional modes of communication and expression. This operational guilt was also rationalized through stories we told ourselves, that we were there to help bring folks into what we considered the good life, the "right" way - our way.

The year that followed my interaction with the healer was characterized by recurrent infection. Two weeks after cycling off of antibiotics, my throat would swell and I would curse the healer while smoking ni moko and drinking kaokioki, the palm wine made from fermented toddy, with my island buddies. The doctor in the capital would send more pills to the island for me to begin taking, and the infection would die down.

After a year, the doctor called me to the capital, and I was diagnosed with tonsillitis. I would need to have my tonsils, and the abscess within, removed. Travel was arranged for me to fly to Australia where the nearest approved medical facilities were located. I remember the disbelief of my friends on the island at the time - that I was going to be flown to a hospital far away to be treated, something that at the time I didn't reflect on all that much. One friend put it plainly - "why don't we get to go to Australia when we are sick?" The answer to that question escaped me at the time, but the question cut to the bone. It exposed to me the power differential inherent in our relationship, by my presence in their land, by the arbitrary nature where we were each born. To be born in the United States meant power on the global stage - to be born in Kiribati meant something else.

My second day after arriving I sat with a nose throat and mouth specialist in a Brisbane high rise to assess the swelling and recurrent fevers. He asked me to tell him what was going on, and I told him the now polished story as we sat. I left out the Kava and smoking, but included the hallucinations, the dehydration, the healer nearly killing me, and the cycles upon cycles of antibiotics.

He shook his head and smirked from behind the sheen of his wooden desk. He looked me in the eyes and nodded, "I think she was right, you know."

I was confused, "Who was right?"

"The healer" he said.

"What do you mean, right?"

The specialist raised his eyebrows and shrugged. "Well, from what you have told me and from what I can see in your files here, she crushed an abscess in your tonsil in the village. That was what all the pressure and reaching into your throat was. That woman knew what she was doing. She didn't almost kill you. She might have saved your life."

I listened, but found it difficult to swallow. Was he right? His tie, white medical jacket, and knowledge seemed to validate what he said. We were on the same team. He had to be right.

He continued, "Frankly, I am amazed that the others did not see it." He cocked his head to the side and half smiled, "Did you tell them the whole story?"

I gazed out the window at other high rises, "I don't know." 


\section{The Whole Story?}

It therefore becomes evident that a conversion or a social revolution that actually transforms consciousness requires a traumatic change in a man's story. The stories within which he has awakened to consciousness must be undermined, and in the identification of his personal story through a new story both the drama of his experience and his style of action must be reoriented (Crites, 2001, p. 43).

On reflection, the Australian specialist in this story is an epistemological gatekeeper. As a Western authority in matters related to medicine, the specialist's interpretation of my experience with the healer changed my subjective reflection upon my position. However, the validation of the healer's knowledge was only official through the interpretation of the Western lens. By interpreting the actions of the healer as harmful in the village of Notoue, I reified a familial narrative that I was not conscious of at the time, in which western medicine, the developed world, and my own narrative self were right, and of value.

In hindsight, I was pulled into the orbit of this narrative and worldview by my parent's professional roles in the medical field. Beyond this, the long shadow of my father's cryptic tales and artifacts from his time as a U.S. Peace Corps volunteer in rural South Korea in the early 1970s played a large part of why I was even in the Republic of Kiribati to begin with. According to Goodall (2004), this phenomenon can be thought of as "narrative inheritance." Narrative inheritance applies to the ways in which rules are established in the traditions of what we talk about in our families, and what we tell of our families and our inner lives to others.

In hindsight, the healer's gender was at odds with my socialized image of a doctor as well. The doctors I knew and visited growing up were uniformly men, the Australian specialist was a man - but the healer was a female. On one level, the rules of who was to be trusted with medical interventions were gendered.

Beyond the dimensions of how my own familial inheritance molded my actions and perceptions, there were other issues that bothered me. Looking back, I thought about my friends there, who asked me why they couldn't visit the United States while I was able to work and live in Kiribati without any issues or why I was able to obtain medical services in Australia while they had to rely on limited resources. In hindsight, all of these pieces pained me from the vantage of the present, but in the moment had little to no significance.

This process of retroactive sense-making aligns with Freeman's (2010) thoughts, that we yearn to make meaning of our lives, and so we narrate and make sense of perhaps nonsensical pieces of information. The memories above are summoned as meaningful because of my analysis in the present, belying the fact that that what took place was not nearly as meaningful in the pure "historical truth" of the experience.

In this case, the episodes recalled with the healer and the year or so after are accorded significance that did not exist at the time, and it is only through their relation to other memories and the present that the current meaning can be discerned. As interpretation and subjectivity are retroactively applied to these memories, in part to rationalize my present position, there is plenty of room for revision and a degree of confirmation bias. Freeman (2010) speaks to this point, "We tend to be historical simplifiers, even reducers, who often skate over the relevant facts in order to lay blame somewhere rather than everywhere or nowhere" (p. 40). Concerns such as fundamental attribution bias and hindsight bias are exacerbated by the sociocultural influences that in part determine the narrative we build to make sense of our experiences. These influences force us to gloss over certain details that may be pertinent, or to block out others. Freeman states that blocking 
out certain sensitive details can force some to completely reimagine their memories to rationalize their actions in the present, creating "the screen of willed ignorance" (Freeman, 2010, p. 83).

For me, reflecting on this narrative in hindsight, what am I leaving out of the whole story? Or, is the whole story part of the present now, part of writing toward a future arc of deeper metacognitive perspective?

\section{Canonical Narratives}

I inherit from the past of my family, my city, my tribe, my nation, a variety of debts, inheritances, rightful expectations and obligations. These constitute the given of my life, my moral starting point. This is in part what gives my life its own moral particularity (MacIntyre, 1981, p. 119).

This confluence of socialization and narrative traditions influence the stories we tell, and more importantly, according to MacIntyre (1981), the narratives we construe as "right" and valid. To MacIntyre, these are canonical narratives, the internalized stories upon which worldview and conceptions of morality are built. When considering this, I seek to trace the canonical stories that led me to assume the healer had nearly killed me. What tropes did I find myself locked into? Beyond this, is my later reframing of the narrative falling into a different trope, one in which the naive westerner learns about themselves at the expense of the historically marginalized? Is it possible to present an intelligible narrative to a western audience outside the influence of the canonical norms of that social field? Ultimately, I find the stories that I have presented here - one of ignorance and dismissal of the island healer, one of quasi-colonial relationship to that knowledge, and the present representation of this process as research all lean towards canonical western narratives.

MacIntyre (1981) spoke to this issue of socialized norms in storytelling, stating that narratives need to be placed in familiar context to be intelligible - and perhaps this gravity of intelligibility is a factor in the development of hegemonic norms. This context could be conceived as a matter of tradition, in lockstep with cultural worldview and socialization. If a narrative or story steps out of a certain tradition, it "baffles" others, who may seek to either adapt to it or excuse it as wrong. According to MacIntyre (1981), this is "When an occurrence is apparently the intended action of a human agent, but nonetheless we cannot so identify it, we are both intellectually and practically baffled" (p. 209).

"Baffling" narratives illuminate the problematic process of accepting stories from different cultural contexts outside of our own, and the disciplining of the narratives to closely resemble those that are told within our preferred social field. Beyond these larger discursive influences, there are certain structural facets of stories that are contextually bound. According to Hart (2011), there is a rhyme and a reason to the stories we pay attention to and tell that are dependent on social field. The narratives we are comfortable with tend to follow similar patterns because we are used to them. In general, Western narratives often offer a plot revolving around setting, rising tension, conflict, and a resolution.

In this narrative, and in my perspective at the time - the healer, the island, and the developing world were baffling, and wrong, building towards a conflict and resolution. Only through the validation of the island knowledge by a western male authority (the Australian specialist) was I able to find intelligibility in the story at the time, and then at the present this story became something different - but still formed in the shadow of intelligible canonical narratives. Is it possible to maintain intelligibility while stepping outside of the canonical? 


\section{Problems with Memory}

According to Kerby (1991), the contextual nature of how narratives are influenced, distorted, and formed are further problematized by the issue of memory. Kirby cites Bourdieu's (1986) concept of habitus as a driver that tacitly shapes our narratives taken from memory. In this, the meaning we assign to experience, and how we understand our lives is not up to us, but is a social act comprised in relation to the social field in which we live and/or were socialized and educated. To Kerby (1991), what we think is our composed narrative is often an amalgamation of habitus and distorted interpretations of images or understandings of memory. He beckons people to question their narrative truth as a means to critically engage what was actually part of their lived experience. The problematic nature of memory's reliability highlights intersections of psychological processes at play in recalling historical truth. Such problems include misinformation effect, social desirability bias, source amnesia, and false memory.

The process of remembering and making sense of the past in the present is driven by worldview, in part informed by the canonical narratives of socialization and the greater rules of the social field in which we currently position ourselves (Kerby, 1991). The episodic events comprising the story with the healer were edited, revised, and sorted on conscious and unconscious levels. This process forged and molded shards of information into an intelligible story of self and worldview.

Given the close relationship between the concepts of canonical narratives and habitus, I wonder if I am reifying my present interpretation of what is right and of value through cherry picking revised memories dependent upon the values embraced in my current social field - one of academia. Does this story really exist, or is it a healing salve I tell myself and others to access power in the present while operating under the veil of willed ignorance? Is the shadow of the canonical narrative I am writing under one in which perspective change is socially desirable and possible?

\section{Creating an Illusory Hero in Story of the Healer}

These thoughts brought me back to the concepts of Mazzei's (2008) social desirability, the possibility of change, and Becker's (2007) notion of the hero. In the case of social desirability, I wondered if I could know that the story of the healer was true, or if it was a tale crafted to frame the possibility of changing my deep-seated assumptions that stood in the way of greater awareness. Was this change possible? Can I un-learn?

Through the lens of Becker (2007), I interpreted the story with the healer as writing a piece of my own symbolic myth of self-worth. Within the writing process itself, I created a hero in my own likeness. Becker (2007) stated: "His sense of self-worth is constituted symbolically, his cherished narcissism feeds on symbols, on an abstract idea of his own worth, an idea composed of sounds, words, and images, in the air, in the mind, on paper" (p. 1).

As I reviewed my notes and drafts, it seemed clear that I was crafting a narrative in which I was the hero, the exemplar to demonstrate how and what the development of cross-cultural awareness may look like, an abstract idea of my own worth and the worth of this autoethnography. This reflection troubled me, and spoke to the constitutive effect of the conscious and unconscious process of restorying.

In the narrative with the healer I wrote myself into a distinctly performative place (Riessman, 2008). On reflection, there was a person on the page who could perhaps change their worldview due to immersive experience. I began to wonder if the re-framing of cultural socialization presented in the narrative was possible, or just a heroic story I told myself and others. 
This question throughout drove me deeper in reflection and I wondered about my relationship to this narrative representation on the page. I considered the difficulties inherent in change of perspective with more gravity - could I un-learn cultural socialization at the cognitive level to the point where my behaviors changed?

I know that my worldview, in conjunction with canonical narratives and the present social field drive how the episodic events in the story with the healer are arranged on paper. All of these memories these were both consciously and tacitly edited, revised, and sorted for maximum effect. This process forged and molded shards of information into a discernable story of self, worldview and, according to Becker (2007), was an exercise in creating heroic illusions that provide existential meaning. For Becker, we all live under illusions to one degree or another as a means to transcend our personal mortality - and ultimately, I feel that this is the root cause of creating this autoethnographic representation. Ethically, however, there is more to consider.

\section{Narratology of the Story with the Healer}

Part of the ethical rationale for this representation to the reader is the heuristic structure of the narrative presented. The story with the healer is situated in a western social field, and engages reader habitas and canonical cultural narratives from that perspective. Only later does the story reveal a new, transformative interpretation of what took before. This narrative device, when employed strategically, deepens metacognitive understanding - in other words, it is a surprise ending. In providing a subtle vehicle for readers to overextend their application of cultural narrative and worldview during the reading, to later reveal this erroneous application, creates what Tobin (2018) described as a "well-made" surprise. Well-made surprises have long been used by writers to narratively engage readers - the genre of mystery novels is built upon such devices. However, a quality surprise ending, which is what arguably makes the above story with the healer interesting and memorable, is a revelation in which an entirely new interpretation of events that have already transpired seems not only compatible with the previously experienced understanding of events, but in actuality feels like a superior, more correct understanding of the events as well. To me at the time, and perhaps to the reader on first viewing, it is difficult to envision the healer could be correct in her treatment due to the gravity of the canonical narrative of western medicine's superiority over indigenous approaches and the habitus of the western social field. In my own case, my perceptions of the situation were gendered as well.

Tobin (2018) asserted that the key for this surprise to be developed is that information has to be introduced that will be surely misinterpreted or disregarded, but most importantly, still remembered when the revelation comes. In the case of the story above, it could be argued that the lack of symbols is what disorients initially. Without a medical setting, without the labcoats and the shuffling of paperwork, readers can be counted on to reliably misinterpret the unknown symbols, actions, and behaviors as baffling and wrong due to the unintelligibility of the setting. This overextension of worldview when encountering baffling settings is known as the "curse of knowledge".

The "curse" is in part why narratives such as these are reliable pedagogical tools, due to the power of canonical narratives, habitus, and the tendencies of human cognition to heavily influence our first interpretations of situations that are foreign. Teasing out these tendencies through autoethnography is a prime place for researchers to visit because readers are not able to completely control or suppress their initial impressions due to the deeply entrenched cultural narrative directing their initial understandings. Also, the condensed format allows participants to recognize their misinterpretation without too much time elapsing for the distorting psychological dimensions of memory to settle in (Freeman, 2010). 
Thus, narratives such as these subtly harness the curse of knowledge to create a surprise revelation that has pedagogical potential to further metacognition for the reader. According to Tobin (2018), the ethical rationale of this narrative sleight of hand must be approached in the spirit of fair play, with clear goals and outcomes in mind for the reader, or else they simply feel tricked for no reason. Ideally, when the surprise is revealed, the readers will not feel victimized by the twist, but gratified by a deeper awareness of their own cognitive process and the pull of canonical narratives and habitus.

This narrative device, of invoking reliably vulnerable cultural assumptions to be later be revealed as erroneous, helps illuminate how autoethnographic research can be both memorable and educative, much in the way that movies or novels employing similar narrative devices for surprise are renowned and remembered by readers. This pedagogical dimension bolsters the ethical case for presenting narratives where scruples of representation are present - the goal is to deepen metacognitive awareness of the curse of knowledge and perhaps prepare folks for future baffling situations.

\section{The Ethics of Social Performance}

Ethical questions emerge in relation to my role in appropriating and representing my own interpretation of the story with the healer and the folks I knew many years ago in the Republic of Kiribati. Such critiques are not new to the field of autoethnography (Atkinson, 1997). As a starting place, the ethical question begins with my fundamental representation of self. The dialogical performative lens of Riessman (2008) works as a starting place. As an autoethnographer I am interested in "who an utterance may be directed to, when, and why, that is, for what purposes?" (Riessman, 2008, p.105). According to Riessman (2008), dialogical performance analysis of narrative is rooted in Goffman's (1978) anthropological notion of social performance. In social performance analysis, the narrative is read to reveal the "preferred self" being presented. As outlined above, there is a narcissistic existential dimension to the story to begin with, along with the influence of canonical narrative structure and habitas. Those aspects do not make the story ethically rationalized. The question then is: What purpose am I am conveying in this narrative beyond my own illusory existential worth?

As the arbiter of the narrative, I am interested in the ethics of representation, but also in reflecting on how I have interpreted and presented the narratives written about the story with the healer. This is a discussion not only of how the narrative and the utterances within are directed and for what purpose, but also how I as researcher ethically rationalize my interpretation and representation of this narrative performance.

The iterations of the story with the healer presented here vary, with versions at first told to Western friends in Kiribati, then later to the specialist in Australia, and now in the context of autoethnographic analysis. These highlight the role of audience, echoing Hart (2011) and Goffman (1963) in the assertion that there is a rhyme and a reason to the stories I tell. Each variation is and was tied to the preferred message I wanted delivered to the audience at the time. The narrative I am comfortable telling and listening to at the present provides a picture of my preferred self - of a reflective autoethnographer committed to leaving no stone unturned. However, in the original story, my purpose was different. Originally, the story provided validation of my socialized habitus, as a way to create an intelligible story of existential heroism. Now I feel the moral is the opposite, to present a narrative that problematizes the process of how we create intelligible stories and the myriad mechanisms involved, and to present a heuristic device. 


\section{Deontological and Utilitarian Ethical Frameworks in Narrative Exchange}

An ethical qualm I have begins with representation in the story, with the continued reinforcing of certain tropes that inform the narrative. For example, the description of the impoverished conditions in the republic of Kiribati, and how this in some ways in integral to invoking the habitus of the reader as part of the well-made surprise to come later. I know these are the realities my memories presented, but I still give pause with perpetuating this representation in the story, especially as it is partly employed deceptively - certainly a point to weigh in ethical scrupling.

Other issues with representation relate to the healer. Was I perpetuating colonizing canonical narratives where faraway lands are mined for knowledge to further enrich and enlighten the powerful? The narrative as presented lends itself to this power dynamic, and it gives me pause. I wondered if my goal in bringing such lived experiences out of the world and to an audience could offset some of this perpetuation, but there needs to be significant purpose to offset this issue.

To visualize the ethical dimensions of how colonizing stories such as those represented by my interaction with the healer and the Republic of Kiribati are ethically permissible, I have a placed my options regarding the different actions I can take on a spectrum ranging between deontological categorical imperatives and consequentialist utilitarian stances.

On the side of deontological reasoning, there would be no cases in which colonial narrative representation is permissible. The absolutism of deontological reasoning is a difficult ethical stance to envision in relation to autoethnography, as most stories depend upon others interpreted through the eyes of the researcher.

That being said, thinking and wrestling with the absolutism of a deontological ethical stance in relation to how stories and settings can be colonized by the dominant group is important to consider. However, on the other end of the spectrum, to slide too easily towards consequentialism in rationalizing representing such stories can be overly paternalistic on behalf of the autoethnographer.

\section{Utilitarianism}

On the other side of the ethical spectrum lies utilitarianism, where the representation of such a story is permissible if the outcomes for the many are desirable. In this sense, the ends justify the means. Classic utilitarianism states that the degree of acceptable representation is proportionally related to the amount of benefit it brings to the greater good.

Thus, if the story only benefits a few, then it is not as ethically just. However, if the narrative shared in question benefits a number of people, then it can be increasingly ethically rationalized. However, who determines what is of benefit is also another ethical issue wrapped up in power and paternalism, or telling others what is in their best interests.

The arguments against utilitarian and paternalistic claims are that the rights of the individual are devalued to the greater good of the collective, as opposed to the inverse deontological claim where the rights of the individual trump the collective good. In individualistic and competitively meritocratic societies such as the United States, the collective cultural "we" often pales in comparison to the powerful "I" (Hofstede et al., 2010). This is another example of a canonical narrative at play in the ethical decision making of autoethnographers scrupling with decisions of whether to represent others.

Thinking about where I positioned myself in rationalizing my representation made me wonder how this individualistic cultural facet informs my ethical framework for decision making in relation to storytelling. It reminded me of the nefarious ethical cousin of classic utilitarianism, a 
stance known as ethical egoism. From this perspective, whatever benefits the individual, the "I", and not the common good, is ethically valid. This is important for any researcher and autoethnographer to reflect on. Does the story I tell benefit the common good? Or is it just benefitting myself? As discussed above, there needs to be more to the rationale beyond the existential myth-making of the researcher.

\section{Ethical Case for the Curse of Knowledge and Colonial Narratives}

Does the greater good produced by the knowledge of reading this story rationalize perpetuating the colonial relationship of educating the dominant culture about their metacognition and potential epistemological bias? There are no easy answers for such questions, but perhaps the process of deliberation and analysis presented in this paper is in and of itself a tool of value. Can I weigh what good comes from including this narrative here against the weight of perpetuating the burden of representation?

As an autoethnographer, I have reflected on the question - Who benefits from this research? The potential heuristic benefit of this narrative in its structure and debrief, and the documented ethical scruples, support the idea of ethical transparency in autoethnography. Beyond this, and perhaps most importantly, the Republic of Kiribati is in the throes of existential destruction due to climate change. To humanize and bring forth the knowledge and people of this small nation is imperative to state of the planet awareness. I believe the greater good benefits from this representation, outweighing the utter lack of representation for small island nations such as Kiribati in western media.

\section{Conclusion}

I return to the kia-kia in the republic of Kiribati and think of the healer reaching into my throat for unknown reasons, the pain shuddering through my body. As I reflect on my privileged position of power, of teaching a colonial tongue in a distant land, of unique access to medical resources, of the ability to cross borders - these were all pieces I took for granted. At the time, reifying western canonical narratives and habitas seemed to be at the center of my story with the healer, a way to perhaps bury my own guilt in the face of such a profound power differential separating me from the folks I knew and worked with. The satisfying surprise of being wrong changed my position in relation to the narrative, and through the process of present reflection I continue to hope of informing a future where the curse of knowledge can be increasingly mitigated.

However, I continue to wonder - is change actually a possibility or is this process a healing narrative that rationalizes inaction, a "veil of willed ignorance"? I find myself returning to these questions again and again. I am not content to write myself into a position of action, where I tell myself soothing stories of myth-making and illusions of heroism - there needs to be more, there needs to be comprehensive transformative processes and tacit lessons built into the narratives we tell. Such narrative structures scaffold the metacognitive means to break from the orbits of canonical narratives and habitus. Ultimately, I know that writing is but one facet of addressing this question, that awareness is an esoteric exercise without transformative behaviors.

As a researcher, I am troubled by the contingencies of memory, social desirability, canonical narrative structures, ethics, and social performance in representation through the restorying process. Narratives are composed, shared, represented, co-opted, appropriated, (mis)understood, and charged with meaning within myriad social fields. These facets lend themselves to contingencies that post ethical and epistemological questions for autoethnographers. 
The rationale to compose this narrative considers both benefits and risks, with an eye on what might benefit the common good. As researcher, this "good" is supported by documenting and describing how such stories can engage readers in meaningful metacognitive ways through engaging the curse of knowledge, by providing representation of narratives from the edges of ecological ruin, and through demonstrating what measured ethical scrupling and systematic sociological introspection can inform.

In the end, I realized that composing this story and analysis was but a part of a greater process of my own development, reflection, and narrative. It is by no means an end in and of itself. My narrative speaks to the possibility of change, and this change is contingent upon an iterative process of dissonance and reflection, of satisfying surprises, and ethical representation.

\section{References}

Atkinson, P. (1997). Narrative turn or blind alley? Qualitative health research, 7(3), 325-344. Becker, E. (2007). The denial of death. Simon and Schuster.

Bourdieu, P. (1986). The forms of capital. In I. Szeman \& T. Kaposy, (Eds.), Cultural theory: An anthology (pp. 81-93). Wiley.

Crites, S. (2001). The narrative quality of experience. In L. P. Hinchman \& S. K. Hinchman (Eds.), Memory, identity, community: The idea of narrative in the human sciences ( $\mathrm{pp}$ 26-50). State University of New York Press.

Freeman, M. (2010). Hindsight: The promise of and peril of looking backward. Oxford Press.

Goffman, E. (1963). Stigma: Notes on the management of spoiled identity. Prentice-Hall.

Goffman, E. (1978). The presentation of self in everyday life (Vol. 21). London: Harmondsworth.

Goodall, B. (2004). Narrative inheritance: A nuclear family with toxic secrets. Qualitative Inquiry, 11(4), 492-513.

Hart, J. (2011). Storycraft: A complete guide to nonfiction narrative. University of Chicago Press. Hofstede, G., Hofstede, G. J., \& Minkov, M. (2010). Cultures and Organizations: Software of the Mind (3rd ed.). McGraw-Hill.

Kerby, A. P. (1991). Narrative and the self. Indiana University Press.

MacIntyre, A. (1981). After virtue. Bloomsbury Academic.

Mazzei, L. A. (2008). Silence speaks: Whiteness revealed in the absence of voice. Teaching \& Teacher Education, 24(5), 1125-1136.

Riessman, C. K. (2008). Narrative methods for the human sciences. Sage.

Tobin, V. (2018). Elements of surprise: Our mental limits and the satisfactions of plot. Harvard University Press.

\section{Notes on Contributor}

Nick Bardo is an assistant professor of teacher education at Colorado Mesa University. Bardo taught abroad as a U.S. Peace Corps volunteer in the Republic of Kiribati, Guatemala, and China and domestically in New Hampshire, Hawaii, Ohio and Florida. His research interests include cultural simulations in social studies education, teaching global perspectives in teacher education, and narrative inquiry. He can be reached at nbardo@coloradomesa.edu.

Manuscript received April 8, 2021 Final revision received August 15, 2021

Accepted August 16, 2021 